\title{
Applications of Survival Analysis in Assessing Women's Health Status in India: A Revisit
}

\author{
Shalini Chandra* and Akansha Sekhsaria \\ Department of Mathematics and Statistics, Banasthali University, India
}

Submission: May 29, 2017; Published: July 27, 2017

*Corresponding author: Shalini Chandra, Department of Mathematics and Statistics, Banasthali University, Rajasthan, India, Email: chandrshalini@gmail.com

\begin{abstract}
Women's health has always been a topic of concern in underdeveloped and developing countries. Based on the trends and estimates obtained from National Family Health Surveys in India using statistical tools, the government has taken numerous steps towards improving the health conditions of women across all states of the country. One such important statistical tool which is being widely used these days is survival analysis. In this article, we have reviewed the applications of the techniques of survival analysis in determining the factors associated with women's health in India.
\end{abstract}

Keywords: Women's health; National family health survey; Survival analysis

\section{Mini Review}

Survival Analysis deals with the statistical procedures for analyzing data for which the outcome variable of interest is time until an event occurs. An 'event' can be any experience of interest for example, death, recovery from a given disease, waiting time to conception, duration of breastfeeding, etc. In such cases, linear and logistic regression methods do not serve the purpose. The main reason for this is the presence of incomplete observations, which in statistical terms in known as censored observations. An observation is said to be censored when there is some information about the individual survival time is given, but the exact survival time is not known. For example, a woman suffering from heart disease may still be alive at the end of the study. Censoring may happen due to various factors such as loss to follow-up, withdrawal from study, event not experienced until the end of study, etc. It is of two types: Left censoring \& Right censoring. Left censoring occurs when the survival time becomes incomplete towards the left side of the follow-up period and right censoring occurs when the survival time becomes incomplete towards the right side of the followup period. However, most of the observations are right censored For details, see Armitage et al. [1], Kleinbaum \& Klein [2].

In the recent years, survival analysis has found immense applications in all fileds especially health sciences. One such particularly important area of its application is in assessing the health status of women. Women are one of the most beautiful/ delicate creations of God. They need to be taken care of, as the health of the whole country depends on the health of women. Good health of women is very important for the economic growth of a country. India, being a highly populous country, has a diverse population, yet the health condition of women is poor in all domains. The main reason for this is the inequality between men and women. This gender gap was observed by many researchers. For instance, Tiwari [3] analyzed the gender inequality on the basis of gender parity index and found that there was a significant gender bias against females. Sengupta [4] observed that women were far behind men in terms of well being and their well being signifcantly depended on the wealth they possessed. This difference arises even before the birth of a girl child in the family. Son preference is signifcantly high among Indian society, especially in rural areas. Statistics obtained from the Census 2011 revealed that the sex ratio in India is 940 females per 1000 males and the child sex ratio is 927 females per 1000 males. This shows that health of women across the whole country is highly neglected right from the beginning of their life.

The variations in women's health condition occur geographically, culturally as well as socio-economically. Ganjiwale [5] reviewed the issues and challenges of the current health status of Indian women and concluded that the progress of any state depends on the empowerment of women. Women face problems in availing health services in almost all parts 
of the country. Therefore, efforts should be made to ascertain good health for women thus leading them to a brighter future and hence making India an empowered nation, as women empowerment is one of the eight Millenium Development Goals (MDGs) laid down by the United Nations (UN).

To analyze the health status of women, it is necessary to determine the factors affecting the health of a woman. A woman's health can be broadly classified into 3 major domains namely physical health, mental health and social health. These domains can be assessed using the respective indicators. Physical health can be determined with the help of various indicators such as nutrition, prevalence of diseases or morbidity e.g. HIV/AIDS \& Anemia, fertility \& reproduction, menopause, mortality, etc. The indicators used for mental health determination are literacy, work participation, autonomy, etc. Similarly, the important social health indicators are mean age at marriage, empowerment, dowry, domestic violence, etc.

Over the years, researchers from all parts of the world have studied these indicators among Indian women using some or the other statistical tool. For instance, Chatterjee [6] in her discussion paper submitted to the World Bank, studied the relation between health and economic productivity of Indian women. The author documented that the nature of the relationship between women's health and their productivity (physical as well as economic) is multi-dimensional. Also, the author explored the determinants of women's health and identifed the interventions required to improve it. Ravindran [7] discussed some methodological issues of research on women's health and laid down a framework for researchers to conduct research and find out the circumstances that lead to poor health of women. Saha \& Saha [8] performed a detailed study of the women's health status in India for five key issues namely: maternal \& child health, violence against women, nutritional status, unequal treatment of boys and girls, and care quality using data from the National Family Health Survey (NFHS). Hazarika et al. [9] studied the problem of undernutrition among women and identified standard of living and age as the most important risk factors of under-nutrition using multiple logistic regression. Raj \& Ibrahim [10] compared the status of women of North India and Nigeria by proposing an instrument to calculate Women's Empowerment Index (WEI) based on their decision making power and attitude towards wife beating. It was observed that women's autonomy is a very important factor for their empowerment. In another work by Agrawal et al. [11] it is stated that the poor morbidity conditions prevail more among obese or overweight women. This result was obtained using binary and multiple logistic regression.

The most reliable source of data for assessing these health indicators for women in India is the National Family Health Survey (NFHS). NFHS was launched by the Ministry of Health \& Family Welfare (MoHFW), Government of India, New Delhi in 1991 and plays a major role in assessing the health conditions prevailing in India, especially that of women and children. It is one of the largest health surveys conducted periodically across the country providing District, State and National Level estimates of various indicators related to health such as nutrition, fertility, family planning, maternal and child health, etc. The International Institute for Population Sciences (IIPS), Mumbai, acted as the nodal agency for providing technical support and co-ordination for all rounds of the survey [12-15]. Macro International, USA provided technical assistance during all rounds. So far, four rounds of NFHS have been conducted successfully.

The first round of NFHS, commonly known as NFHS-I, was carried out in 1992-93. It collected data on 88,562 households and 89,777 ever-married women in the age group 13-49, from 24 states and the then National Capital Territory of Delhi. The NFHS-1 was a major turning point in the growth in the demographic database for India (IIPS (1995)). It acted as a major source of data for a large number of scientific research. For instance, Narasimhan et al. [16] used data from NFHS-I to compare the fertility estimates of Indian women with those obtained from Sample Registration System (SRS) using different measures of fertility like GFR and TFR. Singh et al. developed Cox models to analyze the effect of breastfeeding on birth intervals in Tamil Nadu, India.

NFHS-I was followed by NFHS-II in 1998-99. The survey covered 92,486 households and 90,303 ever married women aged 15-49 and along with the national level estimates, it also included estimates on all the existing states at that time. It collected additional information on quality of family welfare services, prevalence of reproductive morbidity among women, extent of involvement of women in decision making and domestic violence, which was not collected in NFHS-I. Another noteworthy attribute of NFHS-2 was the collection of data on the hemoglobin level in the blood of women and their children aged 6 to 35 months (IIPS (2000)). Some instances of women's health research using data from NFHS can be seen in the works done by Kishor \& Gupta [17] Agarwal et al. [18] etc.

The third round of NFHS, or NFHS-III, was carried out in 2005-06. In NFHS-III, information was collected from a total of 124,385 women aged 15-49, 74,369 men aged 15-54 and 109,041 households. As an improvement over NFHS-I and NFHSII, NFHS-III gathered information on several new and rising issues, such as family life, education, safe injections, perinatal mortality, adolescent reproductive health, high-risk sexual behavior, tuberculosis, and malaria. Furthermore, for the first time in the history of NFHS, NFHS-III also included in its sample, information from all men aged 15-54. In addition to all this, the survey also collected information on nutritional status along with the prevalence of anemia and HIV (IIPS (2007)). The use of data obtained from NFHS-III can be considerably seen in the works of Ghosh et al. [19], Jatrana \& Pasupuleti [20], Agrawal et al. [21] etc. 
The latest in the series is NFHS-IV, which was carried out in 2015-16. NFHS-IV is yet another improvement over the past surveys in the sense that in addition to the 29 states, it also included the 6 Union Territories for the first time. Further, along with the national and state level estimates, it has also provided district level estimates. NFHS-IV collected data on approximately 568,200 households, 625,014 women and 93,065 men and the whole process has been carried out in two phases with almost equal number of states in each phase. Hypertension and blood glucose measurements were also added in the survey. The findings of phase-I have only been published till date by the Union Ministry of India (IIPS (2016)).

The recent report on the first round of NFHS-IV released by MoHFW revealed that Indian women have shown an overall improvement in various health indicators, yet there is a long way to go in order to achieve the desired health status and empowerment level. The report stated that female literacy has increased in almost all states. There has been an increase in the percentage of women having a savings account that they handle themselves. An increase in the number of women using family planning methods has also been reported. Furthermore, institutional deliveries have increased and fertility has declined, which is a good news. Despite the positive results for these indicators, anemia continued to be a major problem of concern for our women and the awareness about HIV/AIDS has reduced. On comparing the results of NFHS-IV, Vasudevan \& Selvamani [22], observed that on one hand many indicators have shown improved condition such as sanitation, access to safe drinking water, etc. But on the other hand, obesity and hypertension still show alarming change. The health of women and children is still a major concern of NFHS $[23,24]$.

Researchers have also compared the rounds of NFHS to assess the trends in these determinants. For instance, Lahariya \& Khandekar [25] used NFHS-I, II and III as a source to reveal the trend in women's as well as children's health condition in India. Mozumdar \& Agrawal [26] analyzed the trends and determinants of menopause using data from the rst three rounds of NFHS using logistic regression and probit analysis. Such comparisons can also be seen in the works of Arokiasamy [27], Tarozzi [28], etc.

The findings from the surveys have since then be used to make policies on the district, state as well as national level. However, some researchers have also suggested that the maximum use of the surveys is still not being made for desired level of development. The fact that acts as a motivation to work towards improving women's health condition in India is that the surveys have given a positive ray of hope for a healthier future of our women. Thus, if planned and careful e efforts are made in the correct direction, better results can be achieved sooner. Survival analysis has been a very useful tool for identifying the indicators related to women's health. It has helped researchers in obtaining precise estimates of the indicators of women's health in order to draw correct interpretations and has hence contributed to the benefit of the society. As a small overview of the statistical procedures involved in Survival analysis, let $\mathrm{T}$ be a random variable denoting the survival time of an individual and $t$ is any specified value of $T$, then $S(t)$ denotes the survival function and is given by:

$$
\mathbf{S}(\mathbf{t})=\mathbf{P}(\mathbf{T}>\mathbf{t})
$$

which is the probability of a person surviving more than time $t$. There are three methods of estimation of the survival function i.e. Parametric, Semi-Parametric and Non-Parametric methods. Methods in which the distribution of the outcome (i.e. time to event) is specified in terms of unknown parameters are called Parametric methods. In Parametric methods, the survival time is modeled as a function of predictor variables. Some of the most commonly used parametric models are Exponential, Weibull, Gamma, etc. Methods in which no assumption regarding the distribution of the survival times is made are called Nonparametric methods. Some of the most commonly used nonparametric methods are Kaplan-Meier method [29] , Life table method, Nelson-Aalen method, etc. Semi-parametric methods go under the name semi-parametric because as far as time is concerned, they are non-parametric, and since the effects of covariates are still parameterized, there exists a parametric component to the analysis. Some examples are Cox's Proportional Hazards (PH) model and Proportional odds model. Among all the methods of estimation, Cox's PH model is the widely used model in determining the factors related to women's health.

\section{Cox Proportional Hazards model:}

A Cox PH model is a statistical technique for exploring the relationship between the survival of an individual and several explanatory variables (Cox (1972)). It is given as:

$$
h(t, X)=h_{0}(t) \sum_{i=1}^{p} \beta_{i} x_{i}
$$

where $\mathrm{X}=\left(\mathrm{X}_{1} ; \mathrm{X}_{2} \ldots \mathrm{X}_{\mathrm{p}}\right)$ are the $\mathrm{p}$ explanatory variables, $\mathrm{h}_{0}(\mathrm{t})$ is known as the base-line hazard which depends only on time and ${ }_{e} \sum_{i=1}^{p} \beta_{i} x_{i}$ is a term that depends on the covariates but not time. The parameters $\beta_{i}$ are estimated using the method of Maximum Likelihood assuming that each event occurs at a different point of time.

Many researchers have applied the Cox $\mathrm{PH}$ model to determine the factors associated with health of Indian women mainly using NFHS data. For instance, Arokiasamy [27] used Cox PH Model to estimate neonatal, post neonatal and child mortality rates by parity and education of women. Strikingly, the results of their analysis showed that child mortality was lower for uneducated sterilized women with low parity than educated sterilized women of high parity. Singh et al. [30] developed Cox model to analyze the effects of breastfeeding on birth intervals in Tamil Nadu, India and found that breastfeeding was the only significant factor affecting birth intervals. Cox model was also used along with multivariate regression by Fledder johann et al. 
[31] to identify that girls were breast fed for shorter periods than boys and consumed less milk leading to higher risk of mortality. Jatrana \& Pasupuleti [20] examined the association between women's autonomy and birth-to-conception intervals in India using data from NFHS-III and Cox's Proportional Hazards model.

Their results indicated that women's autonomy and education were significant predictors of birth-to-conception intervals. Koenig et al. [32] in their paper found that births to mothers subjected to violence experienced infant mortality risks $70 \%$ higher than those free from such violence with the help of Cox Model. Brajesh et al. [33] in their work to identify the determinants of postpartum amenorrhea found that mothers with a BMI greater than $18.5 \mathrm{~kg} / \mathrm{m}^{2}$ resumed ovulation faster and high mean for duration of breastfeeding than those with a lower BMI using Kaplan Meier method and Cox model. Similar studies have been conducted for women of other countries as well using the [34] Cox PH model, Kaplan Meier method, etc. and have given significant and satisfactory results.

The above literature shows that researchers have found the methods of survival analysis fruitful in identifying one or the other factors associated with women's health. The methods are easy to understand and apply. These days, almost all the statistical softwares like R, SPSS, SAS, STATA, etc, include packages for fitting models using survival analysis methods. More efforts in this direction can prove to be helpful in achieving the goals of ensuring good health for women of our country and thus making India an empowered nation.

\section{References}

1. Armitage P, Berry G, Matthews J (2002) Statistical Methods in Medical Research. ( $4^{\text {th }}$ edn), Blackwell Publishing, USA.

2. Kleinbaum DG, Klein M (2005) Survival analysis: A self learning text. ( $\left.2^{\text {nd }} e d n\right)$, Springer.

3. Tiwari AK (2013) Gender inequality in terms of health and nutrition in India: Ev-idence from national family health survey-3. Pacifc Business Review International 5(12).

4. Sengupta A (2016) Gender inequality in well-being in India: Estimates from nfhs household-level data. Economic and Political Weekly 51(13).

5. Ganjiwale J (2012) Current health status of women in India - issues and challenges. Healthline 3.

6. Chatterjee M (1990) Indian women: Their health and economic productivity. World Bank Discussion Papers.

7. Ravindran T S (1992) Research on women's health: some methodological issues. Development in Practice 2(3): 179-188.

8. Saha U, Saha K (2010) A trend in women's health in India - what has been achieved and what can be done. Rural and Remote Health 10(2): 1260.

9. Hazarika J, Saikia I, Hazarika P J (2012) Risk factors of under nutrition among women in the reproductive age group of India: An evidence from nfhs-3. American-Eurasian Journal of Scienticfic Research.

10. Raj D, Ibrahim A (2014) Factor associated with women's empowerment based on NDHS and NFHS data: A comparative study between Nigeria and North India. Report and Opinion 6.

11. Agrawal , Gupta K, Mishra V, Agrawal S (2015) Women's health in india:
The role of body mass index. Health Care for Women International 36(3): 320-341.

12. IIPS (1995) National Family Health Survey (NFHS)-I, 1992-93. Tech rep, International Institute for Population Sciences, Mumbai, India.

13. IIPS (2000) National Family Health Survey (NFHS)-II, 1998-99. Tech rep, International Institute for Population Sciences, Mumbai, India.

14. IIPS (2007) National Family Health Survey (NFHS)-III, 2005-06. Tech rep, Interna-tional Institute for Population Sciences, Mumbai, India.

15. IIPS (2016) National Family Health Survey (NFHS)-IV, 2015-16. Tech. rep, Interna-tional Institute for Population Sciences, Mumbai, India.

16. Narasimhan RL, Retherford RD, Mishra V, Arnold F, Roy T K (1997) Comparison of fertility estimates from India's Sample Registration System and National Family Health Survey. National Family Health Survey Subject Reports.

17. Kishor S, Gupta K (2004) Women's empowerment in India and its states: Evidence from the NFHS. Economic and Political Weekly 39(7): 694-712.

18. Agarwal K, Agarwal D, Sharma A, Sharma K, Prasad K, et al, (2006) Preva-lence of anaemia in pregnant and lactating women in India. Indian Journal of Medical Research 124(2): 173-184.

19. Ghosh P, Arah OA, Talukdar A, Sur D, Babu GR, et al, (2011) Factors associated with hiv infection among Indian women. International Journal of STD and AIDS 22(3): 142-145.

20. Jatrana S , Pasupuleti SSR (2015) Women's autonomy, education and birth intervals in India-visiting the less familiar. Asian Population Studies 11(2): 172-190.

21. Agrawal S, Fledderjohann J, Vellakkal S, Stuckler D (2015) Adequately diversied dietary intake and iron and folic acid supplementation during pregnancy is associated with reduced occurrence of symptoms suggestive of preeclampsia or eclampsiain Indian women 10(3): e0119120.

22. Vasudevan U, Selvamani Y (2015) Rise of health risks among adults in India: A quick look at nfhs-4 fact sheets. Social Science Spectrum 1.

23. Ram F, Paswan B, Singh S K, Lhungdim H, Sekhar C, et al. (2017) National family health survey-4 (2015-16) Economic and Political Weekly 52.

24. Ram F, Paswan B, Singh S K, Lhungdim H, Sekhar C, et al. (2016) Demographic and health trends in India (2005-06--2015-16) results from phase 1 of nfhs-4. Economic and Political Weekly 51(14).

25. Lahariya C, Khandekar J (2007) How the findings of national family health survey-3 can act as a trigger for improving the status of anemic mothers and undernourished children in India: A review. Indian Journal of Medical Sciences 61(9): 534-544.

26. Mozumdar A, Agrawal PK (2015) Prevalence, trends, and determinants of menopause in India: NFHS 1992-93 to NFHS 2005-06. American Journal of Human Biology 27(3): 421-425.

27. Arokiasamy P (2009) Fertility decline in India: Contributions by uneducated women using contraception. Economic and Political Weekly 44(30): 25-31.

28. Tarozzi A (2012) Some facts about boy versus girl health indicators in India: 1992-2005. CESifo Economic Studies 58(2): 296-321.

29. Kaplan E L, Meier P (1958) Non parametric estimation from incomplete observations. Journal of the American Statistical Association 53(282): 457-481.

30. Singh R, Tripathi V, Kalaivani M, Singh K, Dwivedi S (2012) Determinants of birth intervals in Tamil Nadu in India: Developing Cox hazard models with validations and predictions. Revista Colombiana de Estadstica 35: 289-307. 
31. Fledderjohann J, Agrawal S, Vellakkal S, Basu S, Campbel O, et al. (2014) Do girls have a nutritional disadvantage compared with boys? Statistical models of breastfeeding and food consumption inequalities among Indian siblings. PLoS ONE 9(9): e107172.

32. Koenig M A, Stephenson R, Acharya R, Barrick L, Ahmed S et al. (2010) Domestic violence and early childhood mortality in rural India: Evidence from prospective data. International Journal of Epidemiology 39.
33. Brajesh, Mukesh Ranjan, Nagdeve DA, Chander Shekhar (2016) Determinants and differentials of postpartum amenorrhea associated with breastfeeding among women in Bihar, India.International Journal of Reproduction, Contraception, Obstetrics and Gynecology 5(1): 154165.

34. Cox D R (1972) Regression models and life-tables. Journal of the Royal Statistical Society Series B (Methodological).

\section{Your next submission with Juniper Publishers} will reach you the below assets

- Quality Editorial service

- Swift Peer Review

- Reprints availability

- E-prints Service

- Manuscript Podcast for convenient understanding

- Global attainment for your research

- Manuscript accessibility in different formats ( Pdf, E-pub, Full Text, Audio)

- Unceasing customer service

Track the below URL for one-step submission https://juniperpublishers.com/online-submission.php 